\title{
Achieving Desired Cycle Times by Modelling Production Systems
}

\author{
Marcin Juszczyński and Arkadiusz Kowalski \\ Institute of Production Engineering and Automation, Wroclaw University of Technology, \\ 5/7 Lukasiewicza St., 50-370 Wroclaw \\ 130989astudent.pwr.wroc.pl, arkadiusz.kowalski@pwr.wroc.pl
}

\begin{abstract}
Modelling and simulating discrete production processes issues were discussed in this paper. Electric scooter production line at the start-up stage was analysed. Requirements towards its efficiency were change before the line going on-line. Simulation model used production plans, drafted prior to starting production. It considered among other adding machinery, increase production capacity, process of production and transport, transport routes, layout, material flow, human resources and means of transport.

The manufacturing process was designed to use KANBAN. Hence simulation models including various alternative solutions of Technical and Organisational Production Set-up were used to verify whether 12 minute cycle time was achieved. Modification to the production system included among other interchangeability of workstations and operators. Consequently bottle necks in the production process were eliminated.

The project discussed in this paper proves feasibility and validity of combining simulation of production systems with Lean Manufacturing tools.
\end{abstract}

Keywords: simulation of discrete processes, production system, cycle time.

\section{Introduction}

One of many definitions of simulation is: "Simulation is the art and science of creating representations of a process or system in order to conduct experiments and assessments". [6], [11] Simulation methodologies are most often classified by time. [5], [13] In DESS - Differential Equation System Specification both the states and attributes of the model are being update continuously. In DEVS - Discrete Event System Specification on the other hand, system status is approximated for fixed time periods. Those models may be referred to as time-dependent. System status is recognised using the predetermined time periods, hence attributes and system status may be registered. In case of discrete events, time is registered once system status is changed i.e. at least one attribute of an object changes in the modelled system. Moreover, the DEVS\&DESS method combines the two above mentioned methods.

Simulation has become a commonly used tool to engineer production systems. [3], [9] Modelling by simulation is one of the most important supporting techniques allowing to cut production time of a new product and its market roll-out. Naturally, it is 
possible to investigate real production systems, however, it is not economically viable. Hence additional steps currently used in production system engineering are building best possible simulation model, its validation and computer simulation, review of obtained results testing whether or not theoretical solutions are in fact effective and if necessary making some adjustments.

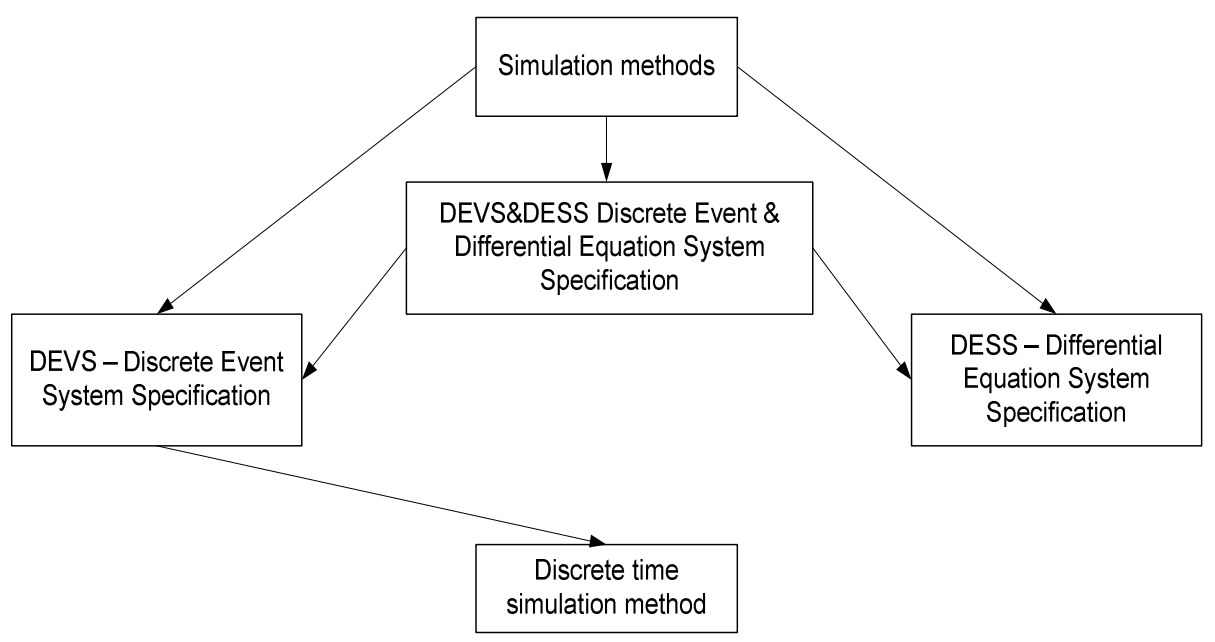

Fig. 1. Classification of simulation methods [13]

Combining modelling with simulation in investigating production processes allows among other to:

- streamline processes and eliminate waste of time and resources,

- improve efficiency and cut production costs,

- analyse and simulate different but critical cases and develop adequate procedures to action,

- create excellent environment for training and understanding processes taking place in an organisation. [1], [2], [7]

Computer simulation is also one of the most important tools for planning production. It allows for addressing market demand in a flexible manner and cut costs of production. [10], [8], [12] Currently available simulation suites are versatile and userfriendly. The most popular systems are FACTOR/AIM, ProModel, Taylor II, Arena and WITNESS. The most useful features include model building environment using predefined graphical elements, considerably improving the process of building a simulation model.

Presented below example projects regarding Technical and Organisational Production Set-up prove it is possible to combine production system simulation techniques with Lean Management tools, here with the Kanban scheduling system. 


\section{Objective of the Project}

The primary objective of the project was to analyse and streamline material flow for purposes of starting-up electric scooter production line.

Simulation models of investigated production system were based on production plans, drafted prior to starting production. It considered among other adding machinery, increase production capacity, process of production and transport, transport routes, layout, material flow, human resources and means of transport. The main criterion for designing the layout was minimum transporting distance for products and materials.

The project took two stages to complete, which focused on expanding production area, adding machinery and increasing manufacturing capacity. The first stage included modelling current layout of the facilities in order to determine current manufacturing capacity and pin-point bottle necks in production lines. The second stage comprised consecutive model modifications until objective defined for particular production cycle was achieved.

\section{Description of Technological Process}

The main production process if the process of assembly. The scooter, assembled on the main assembly line, is fixed to a carrier platform (Figure 2) which is moved by operators between consecutive workstations.

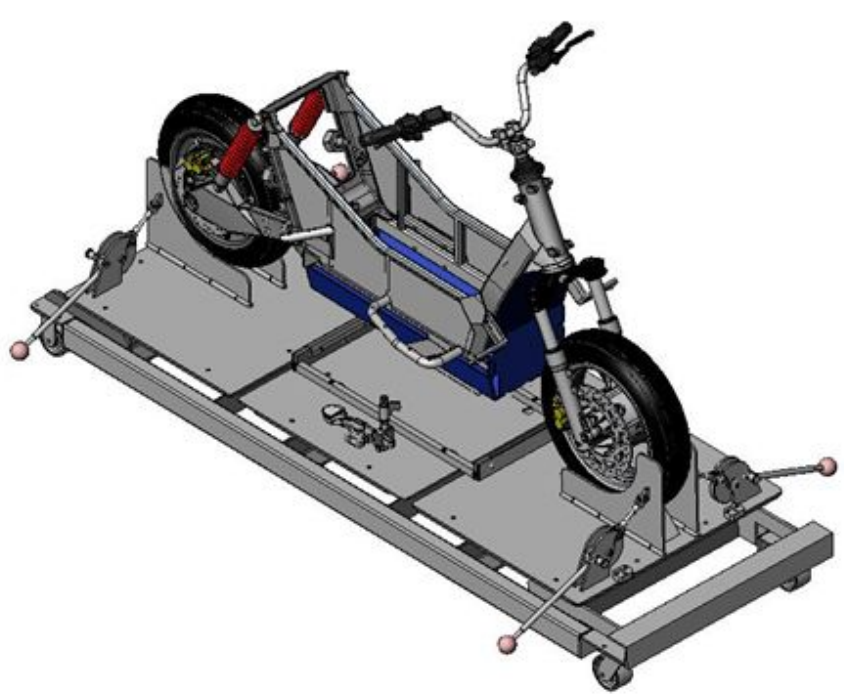

Fig. 2. Platform for assembling the scooter

The platform for assembling the scooter consists of three independently operating surfaces which are lifted depending on currently assembled element. Material flow 
along the assembly line was designed to allow preliminary component assembly in side assembly cells (both left and right to the main assembly line) for them later to be directly moved to the point where they would be assembled on the main assembly line. Below schematically represented in the scooter production line (Figure 3).

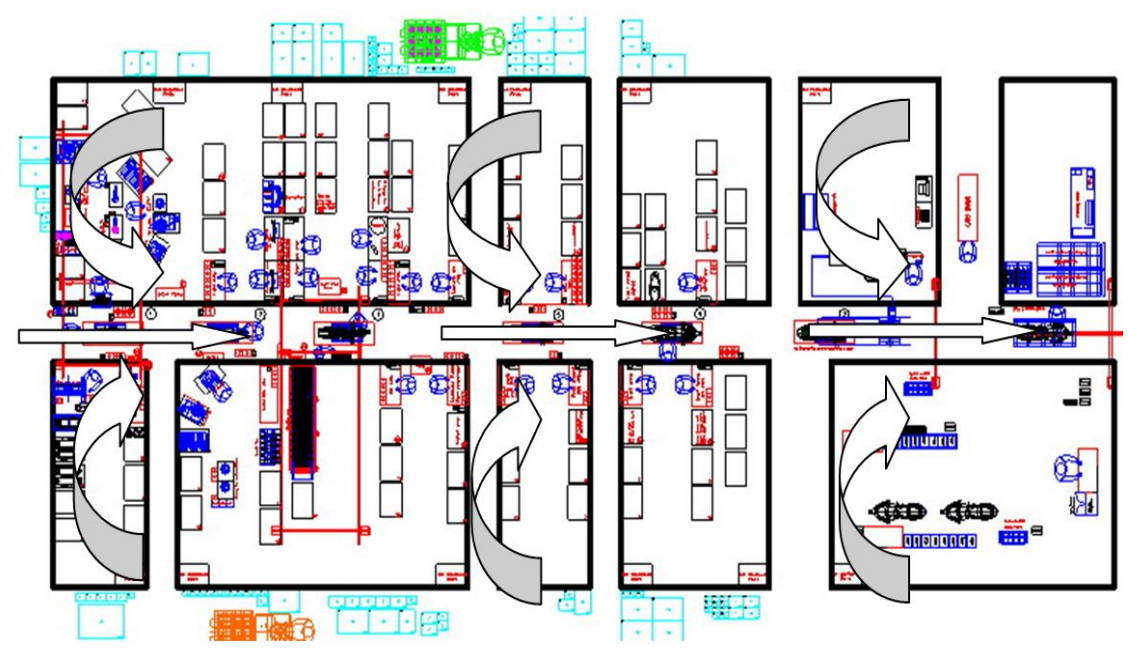

Fig. 3. Assembly line diagram

Each assembly cell uses small pneumatic presses, fixings, assembly tables, power drill-drivers and ancillary equipment. The production line has twenty nine production cells. Seven to the left of the line, eight to the right and fourteen on the main line. Those twenty nine cells consist of sixty six workstations.

Traffic management workstation is also on the shop floor, which stores all tools necessary for the event of production line failure.

\section{Development and Implementation of Production System Model}

ProModel software was used to build the simulation model. Its functionalities enable to effectively simulate production processes by using predefined objects representing workstations, processed goods and production resources [4]. For purposes of discussed project, the graphics library was built with particular attention to details to assure good quality visualisations, whereas the shop floor layout was imported from AutoCad (Figure 4).

Advantages of that solution are among other that the scale of investigated workstation layout is retained, thus allowing later, in simulation software, to factor in real distance travelled by production resources during transport along transport routes. 


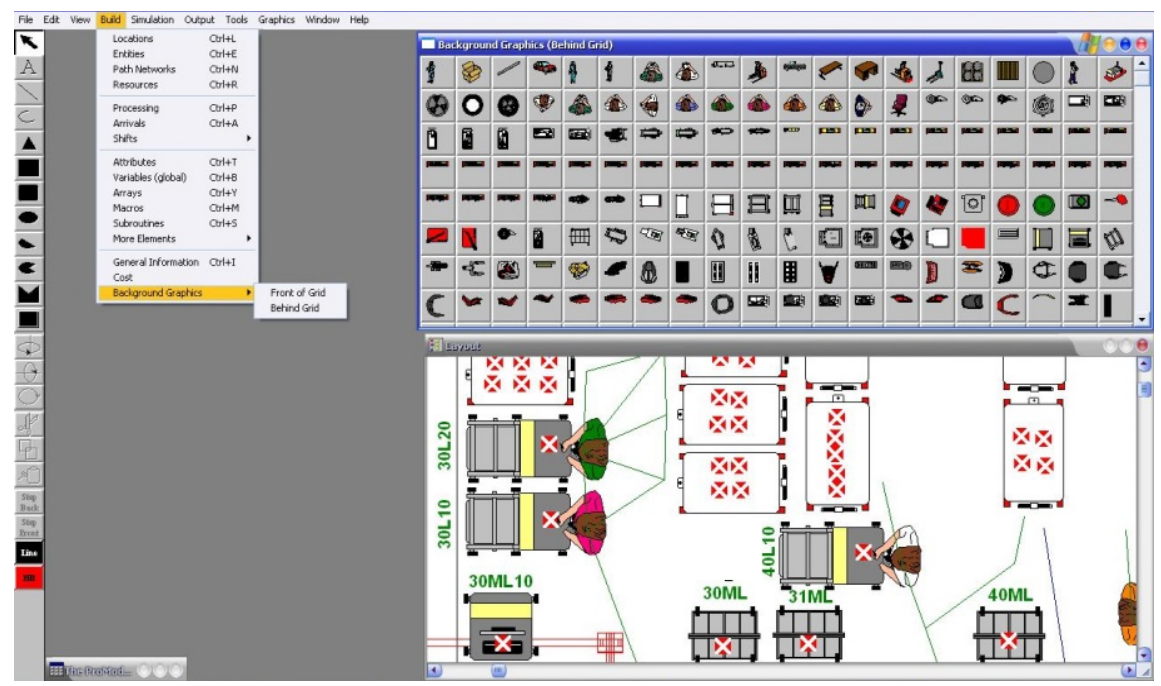

Fig. 4. Simulation model of investigated manufacturing system - workstations

Production processes carried out by individual production cells received the same amount of attention as well as activities completed by individual employees did - Figure 5.

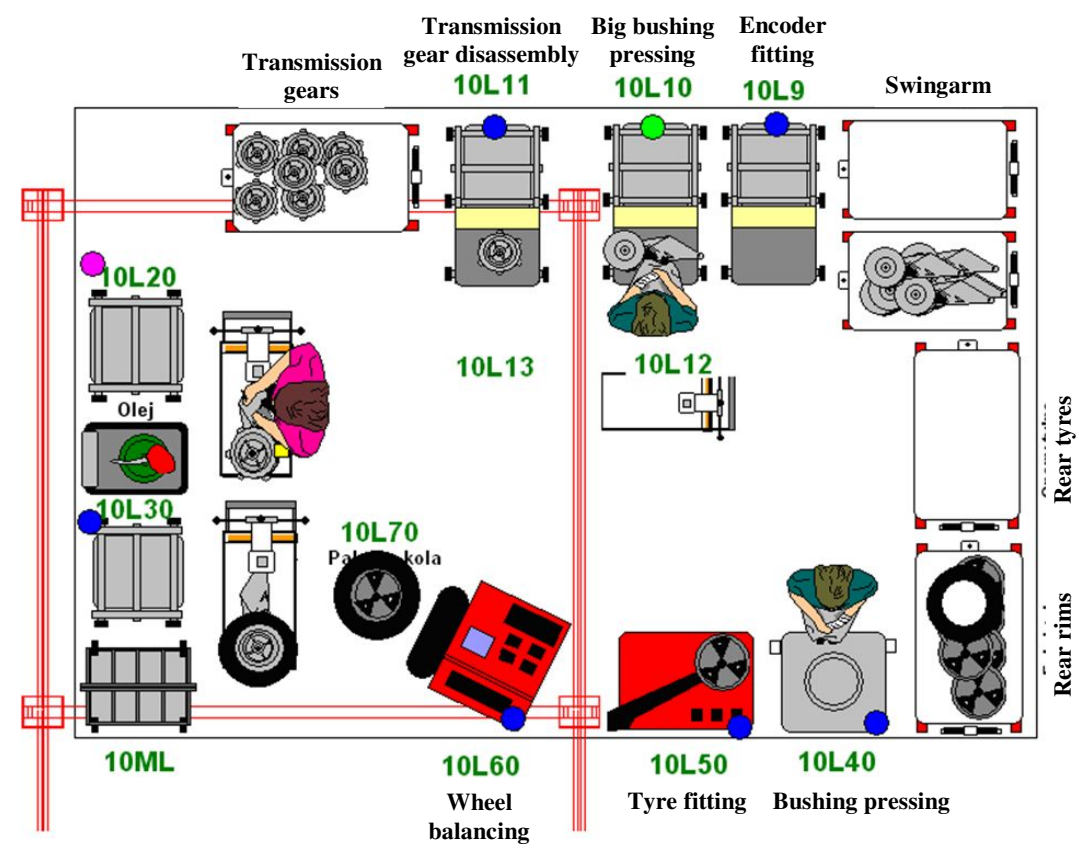

Fig. 5. Details factored into modelling production cells 
For instance, modelling cell 10L included the following activities:

- Worker no 1 - preliminary assembly and encoder fitting, pressing bushing onto swingarm and transmission gear disassembly,

- Worker no 2 - fitting transmission gear onto the swingarm, screwing the breather on, pouring oil and fixing wheel to the swingarm. That worker also transports the swingarm to the main line and fits it to the frame on the platform,

- Worker no 3 - pressing small bushings into rear rim, fitting tyres and wheel balancing on the balancing machine.

\subsection{Stage I - as-Is State}

When building simulation models, it is critical to provide correct data about the modelled production process, e.g. about times of technological operations. Here, time taken by each worker to complete operations at individual stations was measured. Time per each operation was measured three times to calculate an average. Total time of all activities was $354.1 \mathrm{~min}$. Below chart (Figure 6) presents time to completion for operations at individual production cells which were then factored into simulation model.

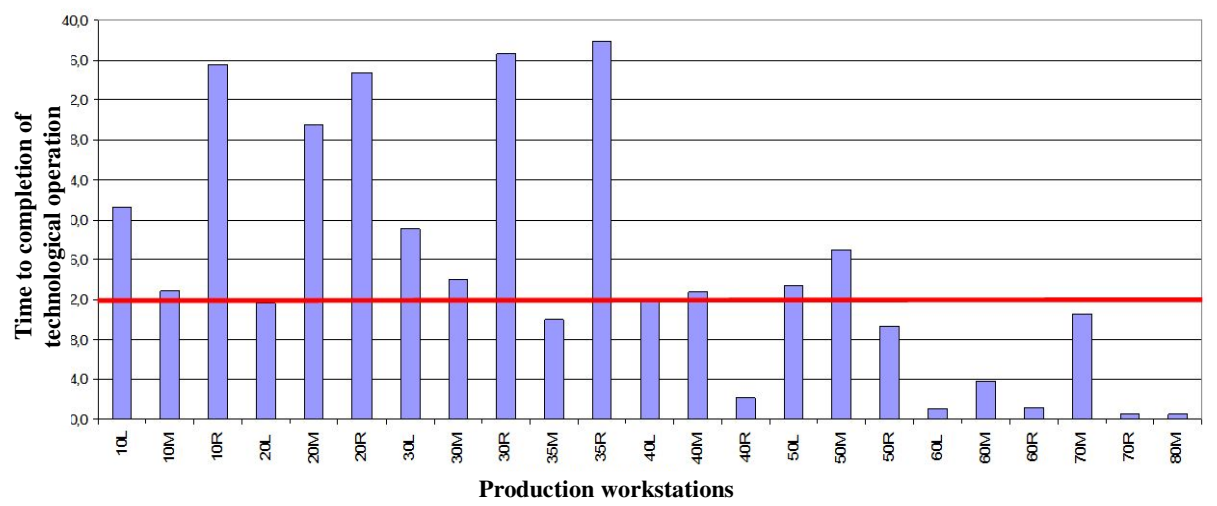

Fig. 6. Time to completion for operations at individual cells

Red line marks the 12 minute target time, which ought to be maintained to assure required cycle of production line. Twelve cells took more time and they were first reorganised. Based on ex-post review of statistics simulation, it was found that workstation utilisation was very diverse. Some workstations are utilised in almost $75 \%$, whereas other in $5 \%$. Worker utilisation, similarly to workstation utilisation, ranges greatly. Obtained data was validated by running it against results achieved by the real production line. Times to completion of e.g. batches of scooters proved negligibly small. 


\subsection{Stage II - Verification of Proposed Solutions}

Impact of modifications and improvements was tested during consecutive simulations of the production system model in order to determine their effect and achieve the objective of 12 minute cycle time. Types of proposed improvements and their performance is presented in Table 1.

Table 1. Types of proposed improvements and their effect

\begin{tabular}{|c|c|c|c|c|}
\hline \multirow[b]{2}{*}{ No. } & \multirow[b]{2}{*}{ Improvement } & \multicolumn{3}{|c|}{ Outcome } \\
\hline & & $\begin{array}{l}\text { Cycle } \\
\text { Time } \\
\text { [min] }\end{array}$ & $\begin{array}{l}\text { No of scoo- } \\
\text { ters } \\
\text { [units/week] }\end{array}$ & $\begin{array}{c}\text { No of } \\
\text { workers }\end{array}$ \\
\hline 1 & $\begin{array}{l}\text { Two workers were added to the } 10 \mathrm{R} \\
\text { cell, where the frame is assembled }\end{array}$ & 44 & 48 & 31 \\
\hline 2 & $\begin{array}{l}\text { Two workers were added for assembly } \\
\text { of ICM (Input Control Module) and } \\
\text { wheel fitting at the main line }\end{array}$ & 43 & 48 & 33 \\
\hline 3 & $\begin{array}{l}\text { Bottlenecks at brake fitting station } \\
\text { were eliminated by adding two more } \\
\text { workers }\end{array}$ & 27 & 71 & 35 \\
\hline 4 & $\begin{array}{l}\text { One worker was added to the } 30 \mathrm{~L} \text { sta- } \\
\text { tion }\end{array}$ & 27 & 71 & 36 \\
\hline 5 & $\begin{array}{l}\text { Two workers were added to the } 30 \mathrm{R} \\
\text { stations and one to the } 30 \mathrm{M} \text { station }\end{array}$ & 26 & 71 & 38 \\
\hline 6 & $\begin{array}{l}\text { Workers were added to the } 30 \mathrm{R} 30 \\
\text { station, where the battery is fitted }\end{array}$ & 25 & 71 & 41 \\
\hline 7 & $\begin{array}{l}15 \mathrm{M} \text { station was added to the main } \\
\text { line. Activities at the } 20 \mathrm{M} \text { station were } \\
\text { partially relocated to the } 15 \mathrm{M} \text { station }\end{array}$ & 17 & 106 & 41 \\
\hline 8 & $\begin{array}{l}\text { Technological operations completed at } \\
50 \mathrm{M} \text { station were redistributed }\end{array}$ & 15 & 114 & 41 \\
\hline 9 & $\begin{array}{l}\text { One worker was added to the } 10 \mathrm{R} \text { sta- } \\
\text { tion where Motor Controller is fitted. }\end{array}$ & 15 & 114 & 42 \\
\hline 10 & $\begin{array}{l}5 \mathrm{M} \text { stations were added to decrease } \\
\text { utilisation of the } 10 \mathrm{M} \text { station. }\end{array}$ & 15 & 114 & 42 \\
\hline 11 & $\begin{array}{l}25 \mathrm{M} \text { station was added to decrease } \\
\text { utilisation of the } 20 \mathrm{M} \text { and } 30 \mathrm{M} \\
\text { workstation }\end{array}$ & 15 & 114 & 42 \\
\hline 12 & $\begin{array}{l}45 \mathrm{M} \text { station was added to the main line } \\
\text { to decrease utilisation of the } 40 \mathrm{M} \text { sta- } \\
\text { tion. }\end{array}$ & 11.4 & 140 & 42 \\
\hline
\end{tabular}

\section{$5 \quad$ To-Be State Final Model}

The final model factors in all 12 proposed organisational improvements. It was then subject to testing in order to verify viability of proposed changes. The final outcome 
was that time to completion of technological operations at each individual workstation was lower than assumed cycle time.

Chart in figure 7 presents time to completion per operation at individual workstations. Notice, times of consecutive operations at each workstation were lower than the initial target time of 12 minutes - the cross-over point is marked by red line. Some workstations take several minutes, hence one worker can attend to several workstations.

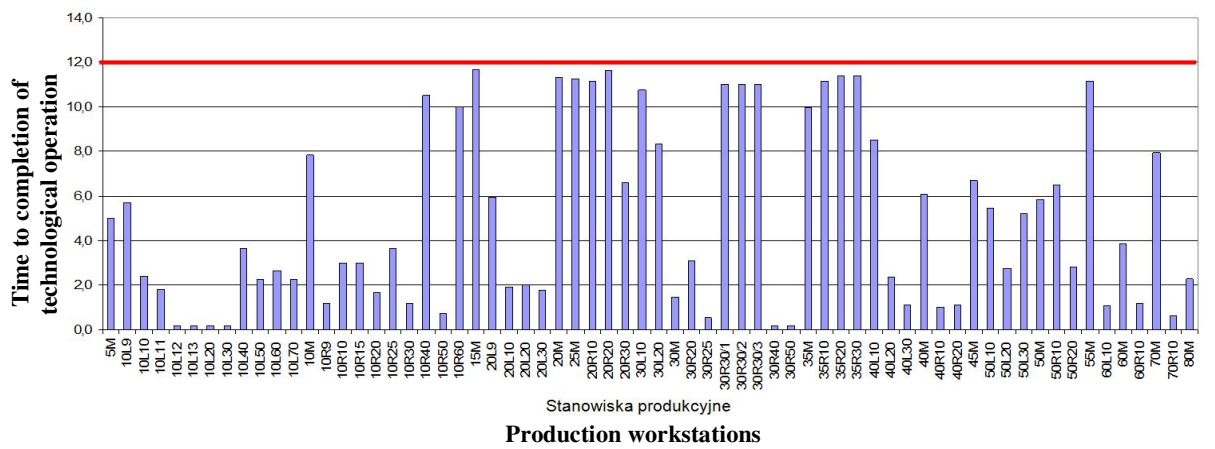

Fig. 7. Time to completion for operations at individual workstations

Figure 8 illustrates, similarly to figure 7 , times to completion of operations. The difference is that figure 7 presents times of individual operations, but at production cells. Said chart shows cells with highest utilisation in terms of technological operations. It is evident, those cells are 10R, 20R, 30R and 35R.

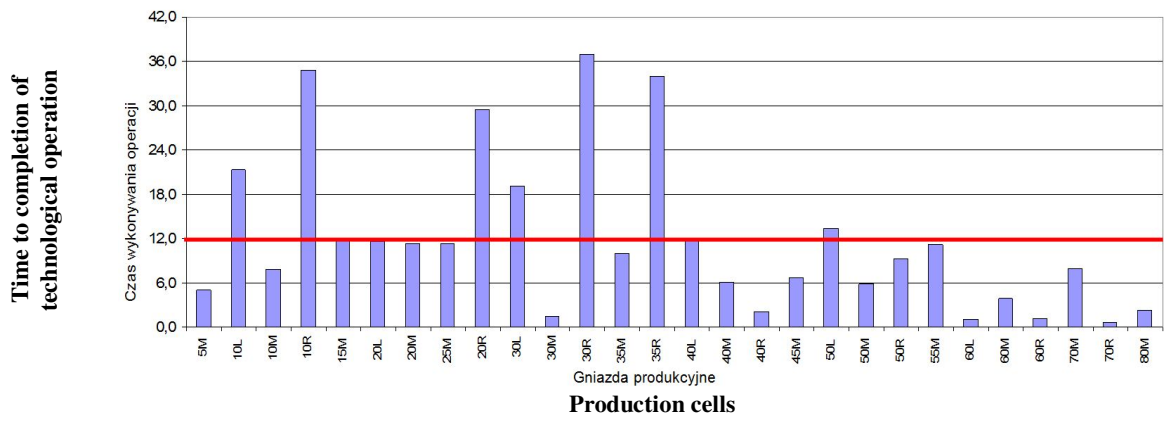

Fig. 8. Time to completion for operations at individual cells

Chart presented in Figure 9 shows the number of scooter and cycle time relative to introduced improvements. Changes made to the production process decreased cycle time, which determines the number of produced scooters. 


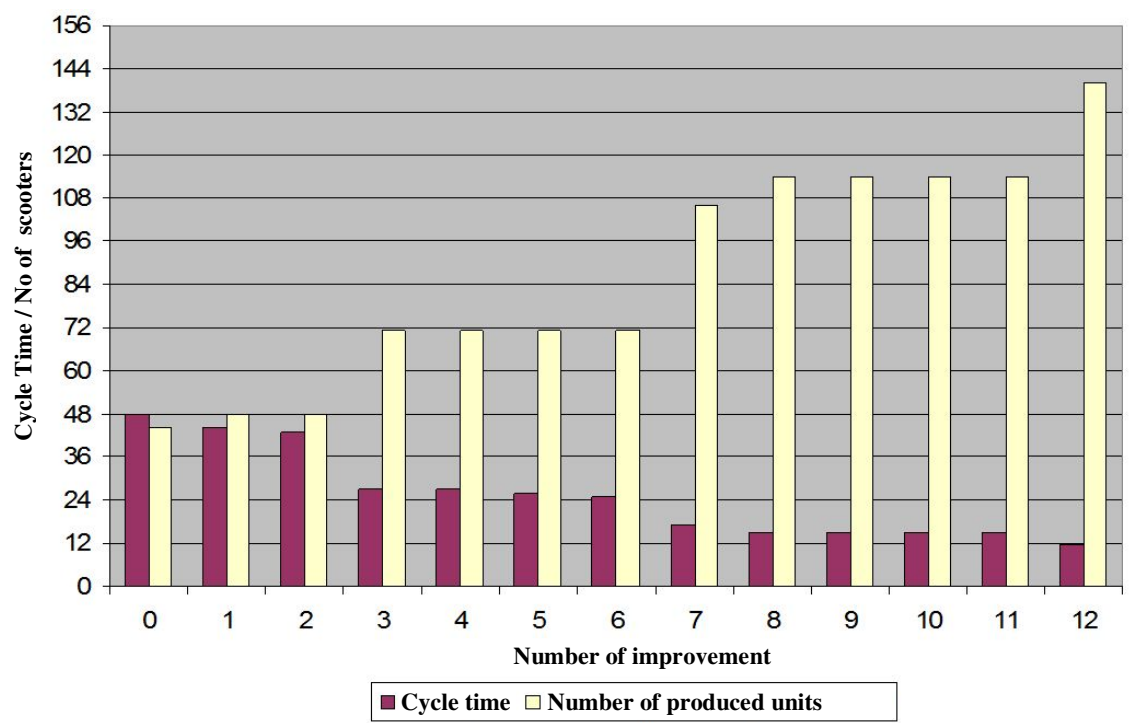

Fig. 9. The number of scooter and cycle time as a function of introduced improvements

The last step of streamlining the production line was optimisation of worker utilisation. Chart showing workstation utilisation before and after changes is presented in Figure 10. The claret colour marks worker utilisation before optimisation, whereas blue colour marks worker utilisation after all the improvements - given 12 minute cycle time.

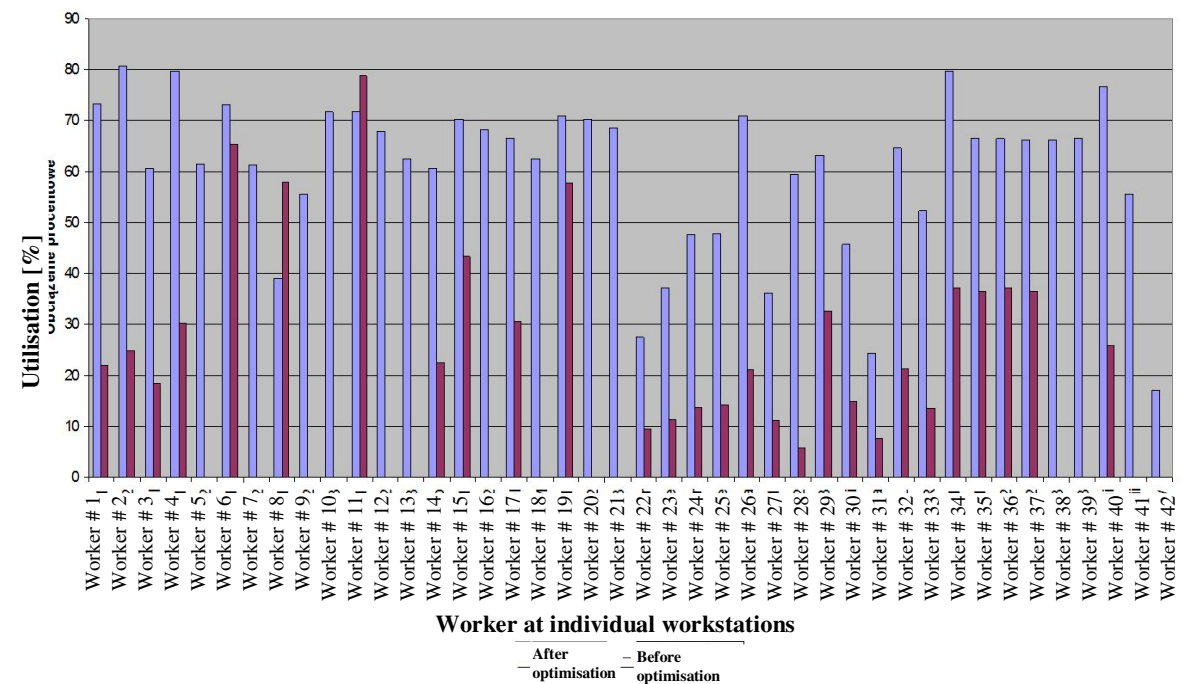

Fig. 10. Worker utilisation before and after optimisation 
For comparing the two simulation models, a function calculating median proved useful. Median for worker utilisation before changes was $24 \%$, whereas after optimisation increase up to $66 \%$ - approx. threefold. The number of workers in the factory grew from 30 to 42 .

\section{Summary}

The project objective was to analyse and streamline material flow for purposes of scooter production line. The main criterion was to achieve a 12 minute cycle time. Reaching target time was possible by making changes to the machinery, increase manufacturing capacity, transport routes and increasing human resources.

The graphics received particular attention. Image quality and resemblance with real objects were prioritised. All workstations, processed goods and lengths of transport routes were modelled to be identical in terms of dimensions and shapes with real objects. The underlying idea was to represent technological process comparable to the real system, thus enabling to obtain detailed information about material flow.

The project was completed in two stages. The first stage included building the as-is state model in order to pin-point bottlenecks and validate obtained results. At the second stage proposed solutions were verified by assessing their efficiency.

An additional outcome of the project - apart from achieving target cycle time was achieving more balanced worker utilisation. Figure 11 presents worker utilisation before and after modifying the production line.

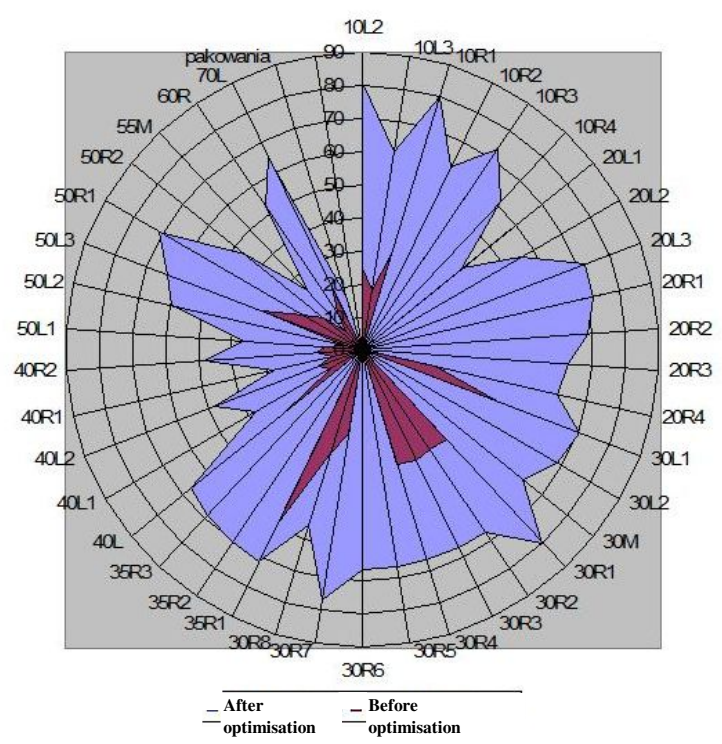

Fig. 11. Worker utilisation before and after streamlining individual production cells 
Pie chart was used for graphical representation of the problem. It shows very distinctly utilisation of individual workers. Worker utilisation before optimisation is marked by the claret colour. Blue colour shows worker utilisation after all the changes and improvements. Here, the blue zone is more balanced. The numbers on the chart mean numbers of individual production cells - the first number, and worker number the second number.

Simulation models and data they generated proved very useful for production system engineering. Initial workstation and resources layout allowed for production of 44 scooters per week, producing cycle time of 48 minutes. After reconfiguration, that time was shortened down to 12 minutes, and the number of scooters rolling off production line jumped to 140 units per week, thus increasing utilisation of resources owned by the company.

\section{References}

1. Biniek, Z.: Elements of the systems, modelling and simulation theoretics. INFOPLAN (2002)

2. Chlebus, E., Burduk, A., Kowalski, A.: Concept of a Data Exchange Agent System for Automatic Construction of Simulation Models of Manufacturing Processes. In: Corchado, E., Kurzyński, M., Woźniak, M. (eds.) HAIS 2011, Part II. LNCS, vol. 6679, pp. 381-388. Springer, Heidelberg (2011)

3. Chlebus, T., Stefaniak, P.: The Concept of Intelligent System for Horizontal Transport in a Copper Ore Mine. In: Corchado, E., Snášel, V., Abraham, A., Woźniak, M., Graña, M., Cho, S.-B. (eds.) HAIS 2012, Part II. LNCS, vol. 7209, pp. 267-273. Springer, Heidelberg (2012)

4. Harrell, C., Biman, K., Bowden, R.: Simulation Using ProModel, Utah (2004)

5. Helal, M.: A Hybrid System Dynamics-discrete Event Simulation Approach to Simulating the Manufacturing Enterprise. ProQuest (2008)

6. Hopp, W., Spearman, M.: Factory Physics, Times Mirror Company, Irwin (1996)

7. Ulrich, K., Eppinger, S.: Product Design and Development, 2nd edn. McGraw-Hill, New York (2000)

8. Krenczyk, D., Kalinowski, K., Grabowik, C.: Integration Production Planning and Scheduling Systems for Determination of Transitional Phases in Repetitive Production. In: Corchado, E., Snášel, V., Abraham, A., Woźniak, M., Graña, M., Cho, S.-B. (eds.) HAIS 2012, Part II. LNCS, vol. 7209, pp. 274-283. Springer, Heidelberg (2012)

9. Law, A., Kelton, D.: Simulation Modeling and Analysis, 3rd edn. McGraw-Hill, Singapore (2000)

10. Tisza, M.: Recent achievements in computer aided process planning and numerical modelling of sheet metal forming processes. Journal of Achievements in Materials and Manufacturing Engineering of Achievements in Materials and Manufacturing Engineering 24(1) (2007)

11. Ören, T.: The Many Facets of Simulation through a Collection of about 100 Definitions. SCS M\&S Magazine (2011)

12. Westkämper, E., Bischoff, J., Briel, R., Dürr, M.: Fabrikdigitalisierung - Ein angepasster Ansatz für die digitale Fabrikplanungin bestehenden Fabriken und Gebäuden, Werkstatttechnik (2001)

13. Zeigler, B., Praehofer, H., Gon Kim, T.: Theory of Modeling and Simulation: integrating discrete event and continuous complex dynamic systems. Academic Press, San Diego (2000) 